\title{
Approche archéologique, environnementale et historique du fleuve Charente
}

\section{Annie Dumont}

\section{(2) OpenEdition \\ Journals}

Édition électronique

URL : http://journals.openedition.org/adlfi/3344

ISSN : 2114-0502

Éditeur

Ministère de la culture

Référence électronique

Annie Dumont, "Approche archéologique, environnementale et historique du fleuve Charente », ADLFl. Archéologie de la France - Informations [En ligne], Poitou-Charentes, mis en ligne le 01 mars 2009, consulté le 01 mai 2019. URL : http://journals.openedition.org/adlfi/3344

Ce document a été généré automatiquement le 1 mai 2019.

(c) Ministère de la Culture et de la Communication, CNRS 


\title{
Approche archéologique, environnementale et historique du fleuve Charente
}

\author{
Annie Dumont
}

Identifiant de l'opération archéologique : 204811

Date de l'opération : 2009 (PC)

1 Les objectifs de ce PCR visent à l'analyse spatiale sur la longue durée d'une portion de fleuve très riche en vestiges, en croisant les données issues de plusieurs disciplines (prospections subaquatiques, géophysiques, bathymétriques, recherches en archives, étude des archéomatériaux et de corpus mobilier). Le site principal étudié dans le cadre du PCR est la zone portuaire du premier Moyen Âge de Taillebourg Port d'Envaux (Dumont, Mariotti, 2009).

2 En 2009, la prospection subaquatique thématique, qui devait porter sur le seuil $\mathrm{n}^{\circ} 5$ a dû être ajournée en raison de mauvaises conditions climatiques. Les études de mobilier et les recherches de comparaisons se sont poursuivies.

3 Le mobilier métallique découvert à Taillebourg Port d'Envaux dans le cadre des prospections subaquatiques a fait l'objet d'une étude détaillée (Mariotti, 2009). Au total, six cent quatorze objets en fer, quatre-vingt-dix-neuf en plomb, cinq en alliage cuivreux et un en argent ont été découverts à Taillebourg Port d'Envaux. La variété du corpus témoigne de la diversité des activités humaines pratiquées sur les bords de la Charente. La navigation et la pêche sont naturellement présentes à travers les outils de batellerie, les ancres, les pierres de lest et les plombs de filet. Les outils de l'agriculture et de l'artisanat donnent des indications sur les autres secteurs en lien plus ou moins direct avec la zone portuaire. Les armes confirment l'importance économique, politique et stratégique du site. Contrairement aux éléments métalliques découverts sur les sites terrestres, les objets issus du fleuve sont globalement bien conservés et une part non négligeable est inédite. Pour ces deux raisons, les objets trouvés en contexte immergé, 
dans la Charente, enrichissent de façon significative le corpus régional du haut Moyen Âge faisant ainsi de Taillebourg Port d'Envaux un site de référence.

4 Le corpus est chronologiquement homogène et son étude montre deux phases bien distinctes: une d'époque mérovingienne ( $\mathrm{VI}^{\mathrm{e}} \mathrm{s} . \mathrm{au} \mathrm{VII}{ }^{\mathrm{e}} \mathrm{s}$ ), avec une représentation faibledes éléments marquants, et une correspondant à la période carolingienne (IX $\mathrm{s}$ et $\mathrm{X}$ ${ }^{\mathrm{e}} \mathrm{s}$.), où les témoins de type anglo-saxon et scandinave sont plus probants. Parmi les objets mérovingiens, on note la présence d'une francisque datée entre la fin du $\mathrm{VI}^{\mathrm{e}} \mathrm{s}$. et le début $d u \mathrm{VII}^{\mathrm{e}} \mathrm{s}$., et deux fers de lance du milieu du VII ${ }^{\mathrm{e}} \mathrm{s}$. On peut ajouter à ces armes d'autres éléments qui se placent dans la même fourchette chronologique, comme plusieurs pirogues et une céramique. Pour les objets de type anglo-saxon et scandinave appartenant à la phase carolingienne, on dénombre deux épées se rapprochant du type $\mathrm{X}$ de J. Petersen datant $d u \mathrm{X}^{\mathrm{e}} \mathrm{s}$. Elles peuvent être associées à trois exemplaires recueillies anciennement au niveau du vieux pont de Taillebourg. Pour les fers de lance, la question est plus délicate puisque l'absence de travaux récents pose problème et amène parfois à une surinterprétation de certains éléments. La typologie de J. Petersen permet de trouver des parallèles avec le monde insulaire et scandinave, même s'il faut émettre des réserves selon les cas. Les fers de lance rencontrés à Taillebourg sont tous datés des $\mathrm{IX}^{\mathrm{e}} \mathrm{s}$. et $\mathrm{X}^{\mathrm{e}} \mathrm{s}$. Trois d'entre eux se rattachent à des types anglo-saxon et scandinave d'après Petersen. Six autres se caractérisent par des ailerons et semblent être soit d'influence carolingienne locale, soit d'influence anglo-saxonne et scandinave. Deux haches appartiennent sans nul doute à la culture matérielle anglo-saxonne et scandinave. La première peut être datée de la seconde moitié de IX ${ }^{\mathrm{e}} \mathrm{s}$. Alors que la seconde se rattache plutôt au Xe $\mathrm{e}$.

5 Provenant du seuil 3, il faut noter la présence d'un marteau qui semble se rapprocher d'exemplaires localisés dans les contextes anglo-saxons et scandinaves, comme à York, et datant de la fin du $\mathrm{X}^{\mathrm{e}} \mathrm{s}$. Ce type de marteau, par sa forme et ses dimensions, pourrait être associé à l'activité d'orfèvrerie. La découverte d'un plat de balance, d'un poids, d'un ciseau et d'un poinçon nous amène à penser que l'artisanat du métal était présent à Taillebourg. Malheureusement, aucune pièce de monnaie n'a encore été trouvée.

6 L'activité navale est bien représentée à travers les pirogues, les restes d'épaves assemblées, les outils de batellerie, deux ancres et des lests de filet en plomb. Ces derniers ont été découverts en nombre lors des prospections subaquatiques. Neuf d'entre eux sont naviformes et rappellent les représentations de bateaux dans l'ornementation anglosaxonne et scandinave. Enfin, quelques éléments en alliage cuivreux atypiques sont à présenter. Parmi eux, un poids de balance qui comporte un assemblage de décor rappelant fortement les influences anglo-saxonne et scandinave, et une bague qui relève de l'orfèvrerie scandinave, peuvent être datés du $\mathrm{X}^{\mathrm{e}} \mathrm{s}$.

7 La détermination d'éléments allochtones, d'origine anglo-saxonne ou nordique, pose à nouveau des questionnements sur les réseaux d'échanges avec l'Europe du Nord et sur la présence scandinave en Saintonge aux IX ${ }^{\mathrm{e}} \mathrm{s}$. et $\mathrm{X}^{\mathrm{e}} \mathrm{s}$. En effet, avec vingt-cinq objets de type anglo-saxon et scandinave, la zone portuaire de Taillebourg Port d'Envaux rassemble la plus grande concentration connue en France et se rapproche des découvertes de la vallée de la Seine et de l'île de Groix. Leur présence est à mettre en relation avec les incursions scandinaves dans la région charentaise mais aussi avec le retentissement de l'axe fluvial que constitue la Charente, passerelle entre l'Aquitaine et le nord-ouest de l'Europe, et notamment avec l'Angleterre. Les sources écrites qui relatent la présence de raids saxons entre la Charente et la Gironde, et les découvertes archéologiques effectuées depuis la fin du XIX ${ }^{\mathrm{e}}$ s., notamment en Charente-Maritime, témoignent des relations 
précoces (à partir du $\mathrm{V}^{\mathrm{e}} \mathrm{s}$.) entre les côtes atlantiques et les "Germains de la mer ", issus des côtes de la Manche et de la mer du Nord. Ainsi, les quarante et un objets appartenant à la culture matérielle anglo-saxonne découverts au sein de la nécropole de Herpes (localisée à $50 \mathrm{~km}$ de Taillebourg) mettent en avant un lien évident entre la Charente et le sud-est de la Bretagne anglo-saxonne dès cette époque (Soulat, 2009).Ce lien peut se traduire par des échanges entre les deux territoires relativement éloignés mais en contact, grâce à la mise en place d'un carrefour de communication entre les ports des côtes septentrionales de la Gaule et l'Aquitaine, (Lorren, 1992). La présence, à Taillebourg Port d'Envaux, d'objets de type anglo-saxon et scandinave nous amène à nous interroger sur le lien qu'aurait pu entretenir ce port, localisé à seulement $40 \mathrm{~km}$ de l'océan Atlantique, avec les grands ports contemporains de l'Europe du Nord et de l'ouest de l'Europe au premier Moyen Âge. Afin de répondre à ces interrogations, une recherche de comparaisons avec les principaux sites d'emporia ayant fait l'objet de fouilles archéologiques est en cours.

8 (Fig. $n^{\circ} 1$ : Fleuve Charente : épées de type anglo-saxon et scandinave)

9 (Fig. $\mathrm{n}^{\circ} 2$ : Fers de lance datés entre le VII ${ }^{\mathrm{e}}$ s. et le IX ${ }^{\mathrm{e}} \mathrm{s}$.)

10 (Fig. $n^{\circ} 3$ : Raids saxons le long des côtes de la Gaule)

11 (Fig. $\mathrm{n}^{\circ} 4$ : Localisation des sites mentionnés dans le texte)

12 (Fig. $n^{\circ} 5$ : Répartition des principaux emporiadans le nord-ouest de l’Europe)

13 DUMONT Annie

\section{ANNEXES}


Fig. $\mathrm{n}^{\circ} 1$ : Fleuve Charente : épées de type anglo-saxon et scandinave

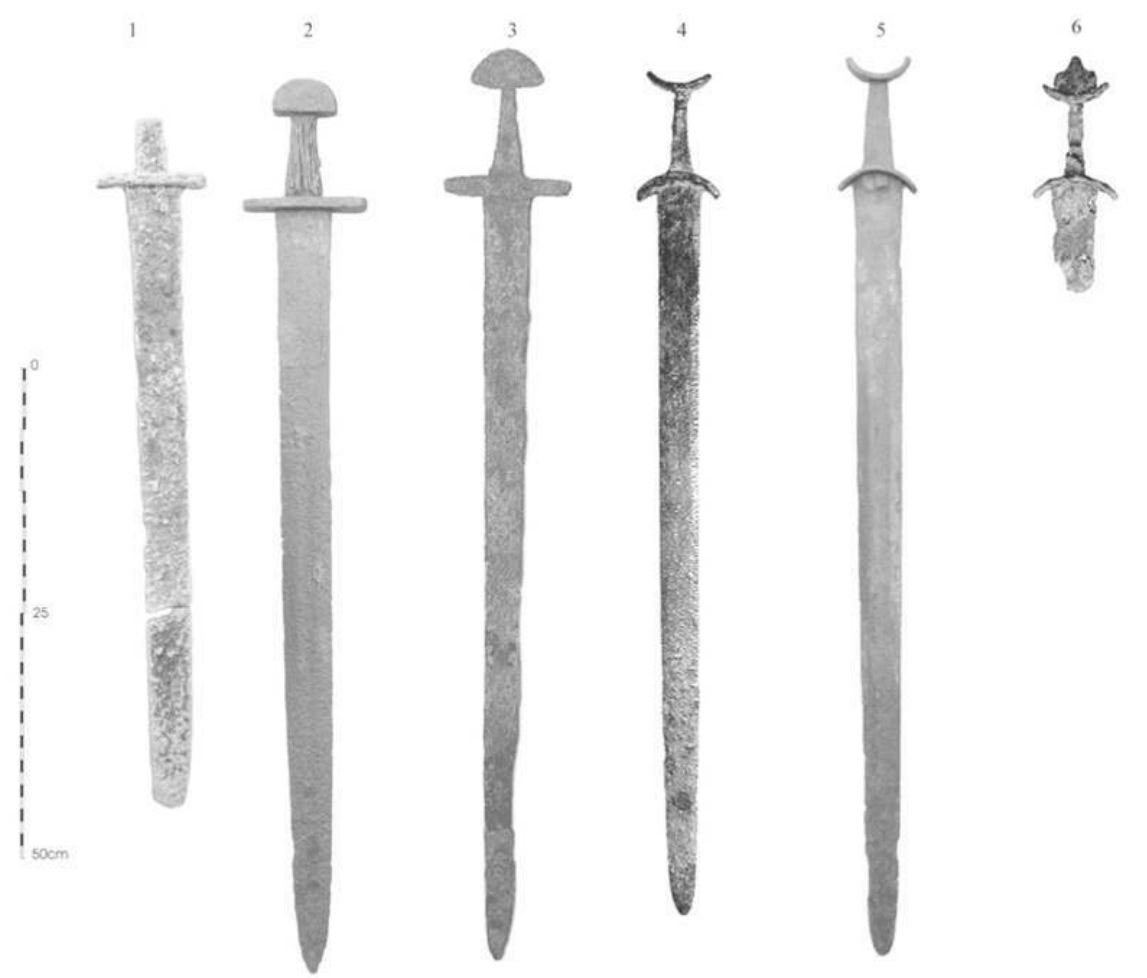

Auteur(s) : Mariotti, Jean-François (MCC). Crédits : D'après Jean-François Mariotti MCC (2009)

Fig. $n^{\circ} 2$ : Fers de lance datés entre le VII'es. et le IX's.

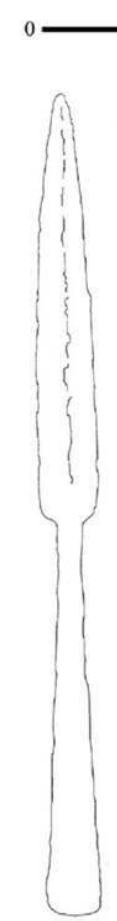

1

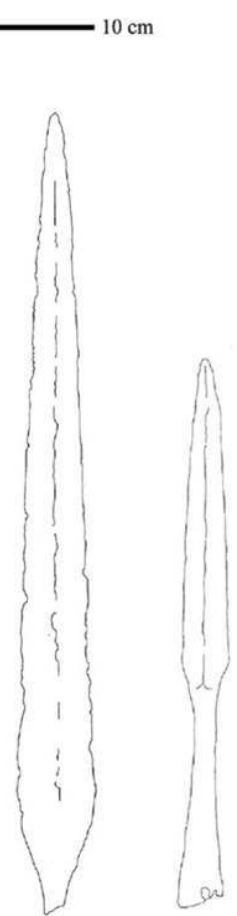

2

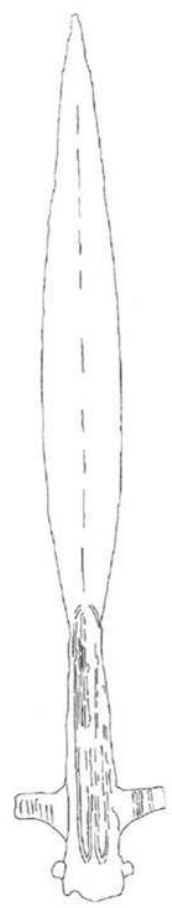

4

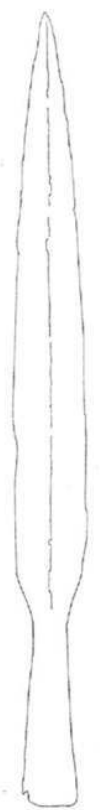

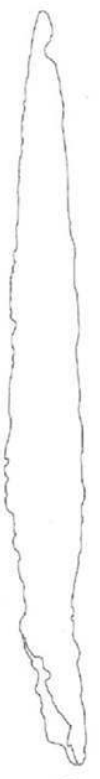

Auteur(s) : Mariotti, Jean-François (MCC). Crédits : Jean-François Mariotti MCC (2009) 
Fig. $n^{\circ} 3$ : Raids saxons le long des côtes de la Gaule

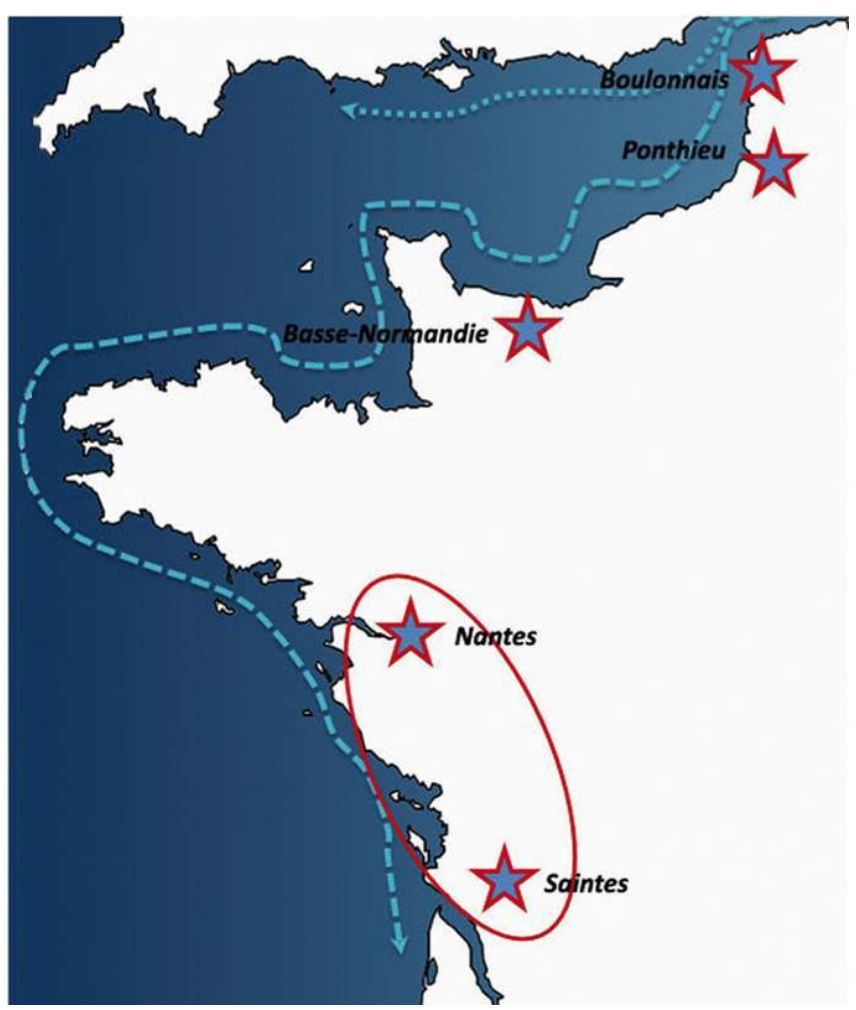

Auteur(s) : Soulat, Jean (UNIV). Crédits : Soulat Jean UNIV (2009) 
Fig. $\mathrm{n}^{\circ} 4$ : Localisation des sites mentionnés dans le texte

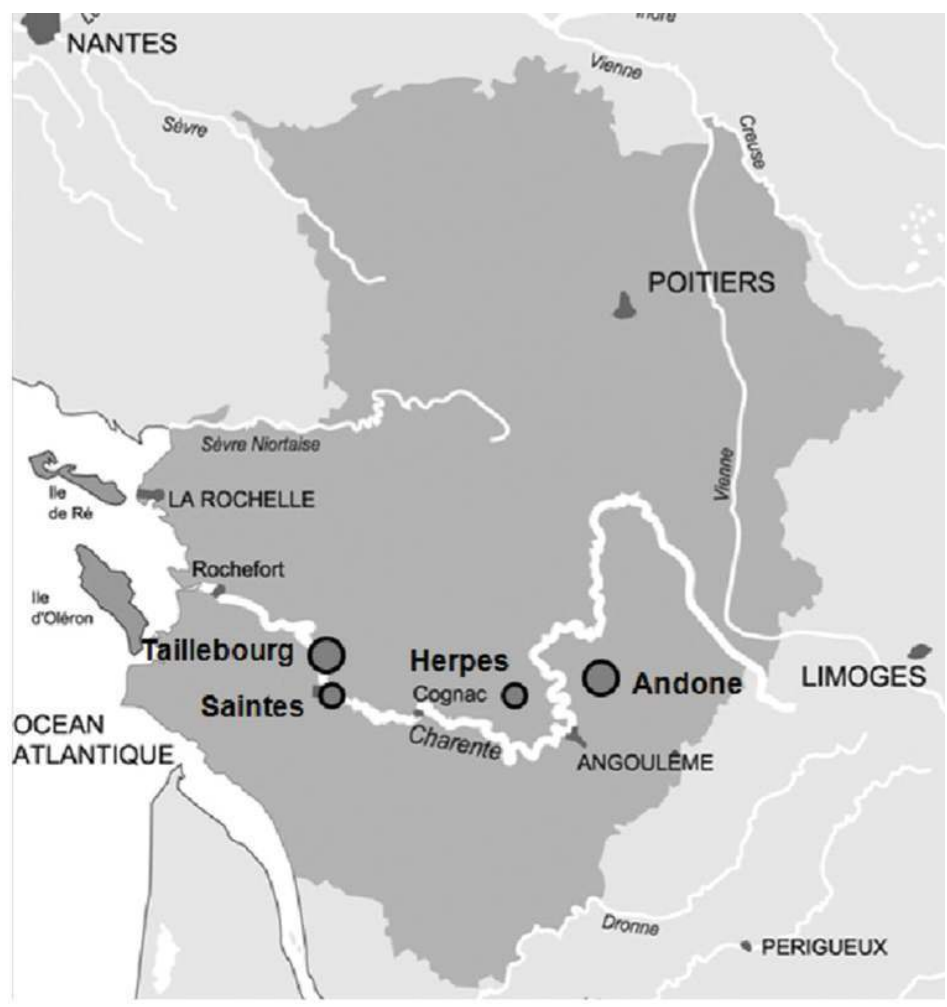

Auteur(s) : Mariotti, Jean-François (MCC) ; Dumont, Annie (MCC) ; Soulat, Jean (UNIV). Crédits :

Dumont Annie MCC, Jean-François Mariotti MCC, Jean Soulat UNIV (2009) 
Fig. $n^{\circ} 5$ : Répartition des principaux emporiadans le nord-ouest de l'Europe

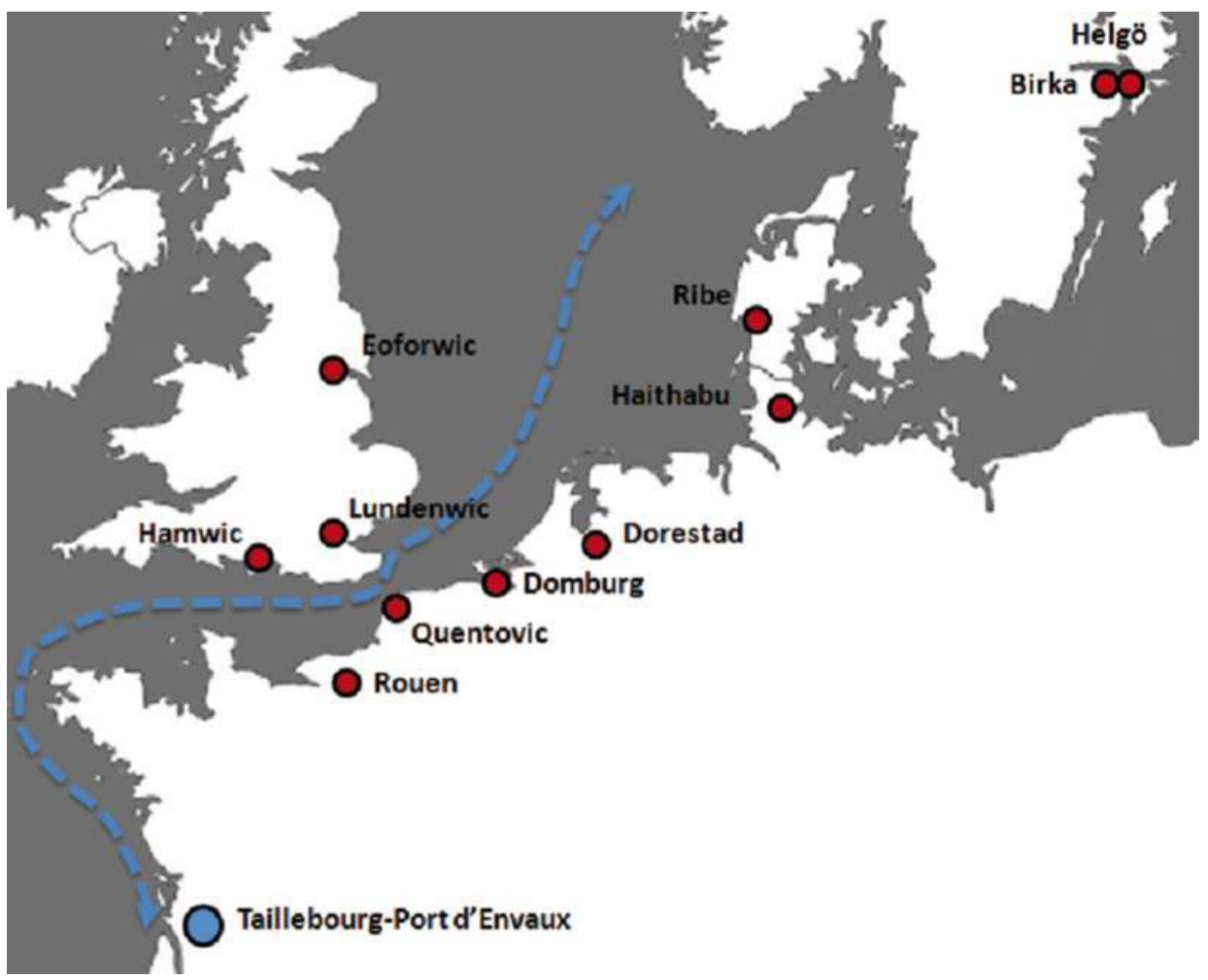

Auteur(s) : Soulat, Jean (UNIV). Crédits : Soulat Jean UNIV (2009)

INDEX

Index chronologique : ép. carolingienne, ép. mérovingienne

Thèmes : activités commerciales, ancre, archéologie subaquatique, argent, arme, artisanat, balance, céramique médiévale, cuivre, épave, fer, filet, fleuve, fonction des sites, francisque, hache, instrument de mesure, lance, marteau, navigation, objet métallique, orfèvrerie, outil agricole, pêche, pirogue, plomb, poids, pont, port, vie politique

Index géographique : Poitou-Charentes, Charente-Maritime (17), Taillebourg, Port d'Envaux operation Projet collectif de recherche (PCR)

\section{AUTEURS}

\section{ANNIE DUMONT}

MCC 